\title{
KLASIFIKASI PENYAKIT KALKULUS ( KARANG GIGI ) MENGGUNAKAN PENGOLAHAN CITRA DIGITAL DENGAN METODE JARINGAN SARAF TIRUAN BACKPROPAGATION
}

\author{
Adi nur rohkhim ${ }^{1}$, Cahyo darujati ${ }^{2}$ \\ Email: adi.04115028@ narotama.ac.id ${ }^{1}$, cahyod@ fasilkom.narotama.ac.id ${ }^{2}$ \\ Fakultas ilmu komputer Universitas Narotama Surabaya
}

\begin{abstract}
Abstrak
Jenis penyakit gigi dan mulut cukup banyak jumlahnya. Mulai dari yang jenisnya ringan hingga yang berat. Salah satu contoh jenis penyakit gigi yang ringan adalah karang gigi. Mungkin kebanyakan orang sering mengabaikan penyakit yang satu ini. Karena alasan tidak menganggu kinerja gigi. Padahal ada beberapa dampak yang di timbulkan ketika karang gigi dibiarkan menumpuk, seperti : bau mulut, peradangan pada gusi, sampai penyumbatan pembuluh darah. Menurut inisiasi dan tingkat akumulasi bentuk karang gigi. Karang gigi di klasifikasikan menjadi 3 bagian yaitu sligt, moderate, dan heavy. Penelitian ini bertujuan untuk mempermudah tenaga medis gigi dalam mengklasifikasi penyakit kalkulus menggunakan bidang keilmuan pengolahan citra digital dan jaringan saraf tiruan backpropagation. Masukan Jaringan saraf tiruan berupa luas area karang gigi, ciri hue, ciri saturation, dan ciri value. Menggunakan 2 hidden layer dengan masing masing masukan neuron berjumlah 100 neuron. Di peroleh hasil tingkat akurasi sebesar $100 \%$ untuk data latih, dan $90 \%$ untuk data uji . Penelitian ini menggunakan 50 data citra kalkulus, dengan perbadingan data latih dan data uji sebesar 60:40.
\end{abstract}

Kata kunci : Pengolahan citra digital, jaringan saraf tiruan backprobagation, penyakit kalkulus ( karang gigi ), klasifikasi

\section{Pendahuluan}

Gigi merupakan organ tubuh manusia yang sangat peting. Selain sebagai alat mengunyah makanan agar makanan mudah dicerna oleh tenggorokan kita. Gigi juga berfungsi sebagai salah satu acuan dasar kesehatan gigi dan mulut oleh badan kesehatan dunia atau WHO. Menurut hasil riset kesehatan dasar ( Riskedsas ) tahun 2018, yang dilakukan oleh kementrian kesehatan republik Indonesa, bidang badan penelitian dan kesehatan masyarakat [1]. Menunjukkan bahwa kesehatan gigi masyarakat Indonesia dalam kondisi kurang baik. Dalam kegiatan tersebut didapatkan data 57,6 \% masyarakat di Indonesia mengalami masalah pada gigi dan mulut serta hanya 10,2 \% yang mendapat penanganan dari tenaga medis gigi. Penelitian ini dilakukan di seluruh provinsi di Indonesia . Provinsi yang paling rendah tingkat permasalahan gigi dan mulut adalah provinsi Jambi, dengan presentase $45 \%$ masyarakat Jambi yang mengalami permasalahan pada gigi dan mulut. Serta 9,5 \% yang mendapat penanganan dari tenaga medis gigi. Sedangkan provinsi dengan tingkat permasalahan gigi dan mulut paling tinggi adalah provinsi Sulawesi Tengah, dengan presentase $73 \%$ masyarakat Sulawesi Tengah yang mengalami permasalahan gigi dan mulut. Serta hanya $8,2 \%$ yang mendapat penangan dari tenaga medis gigi.
Ada berbagai macam jenis penyakit gigi dan mulut, salah satunya adalah karang gigi. Karang gigi merupakan suatu endapan keras yang melekat pada permukaan gigi yang berwarna kekuningan, kecoklatan hingga berwarna kehitaman [2]. Menurut inisiasi dan tingkat akumulasi, karang gigi di klasifikasikan menjadi 3 bagian, yaitu slight dengan ukuran karang gigi mulai $0-1 \mathrm{~mm}$, moderate dengan ukuran karang gigi 1-2mm, dan heavy dengan ukuran di atas $2 \mathrm{~mm}[3]$.

Di era industri 4.0 ini. Teknologi telah berkembang di berbagai sektor kehidupan, seperti bidang pembangunan, bidang pertanian, sampai bidang kesehatan. Ada salah satu bidang keilmuan teknologi informasi yang jarang masyarakat mengetahuinya tapi keilmuan ini akan sering di gunakan di masa yang akan datang. Yaitu pengolahan citra digital atau " digital image processing " dan kecerdasan buatan atau "artificial intelligence".

Pengolahan citra digital definisikan sebagai upaya peningkatan informasi bergambar untuk interprestasi manusia dalam memproses data untuk persepsi mesin. [4]. Sedangkanan Para ilmuan memiliki dua cara pandang yang berbeda tentang Kecerdasan buatan. Ilmuan yang pertama berpendapat AI sebagai bidang ilmu yang hanya fokus pada proses berpikir. Sedangkan ilmuan yang kedua berpendapat kecerdasan buatan sebagai bidang 
ilmu yang fokus pada tingkah laku. Cara pandang kedua ini melihat kecerdasan buatan secara lebih luas karena suatu tingkah laku pastilah didahului dengan proses berfikir. Pengertian kecerdasan buatan yang paling sesuai di era sekarang ini adalah tindakan yang rasional dengan pendekatan agen rasional . Pemikiran tersebut berdasarkan bahwa komputer mampu melakukan berfikir secara logis dan juga mampu malakukan aksi secara rasional berdasarkan hasil penalaran yang dilakukan [5].

Dengan menggabungkan bidang ilmu pengolahan citra digital dan kecerdasan buatan untuk klasifikasi penyakit kalkulus, diharapkan tenaga medis lebih mudah dalam mengklasifikasi penyakit kalkulus secara digital dan dapat menetukan tindakan yang cepat dalam menangangi permasalahan karang gigi.

\section{Metode Penelitian}

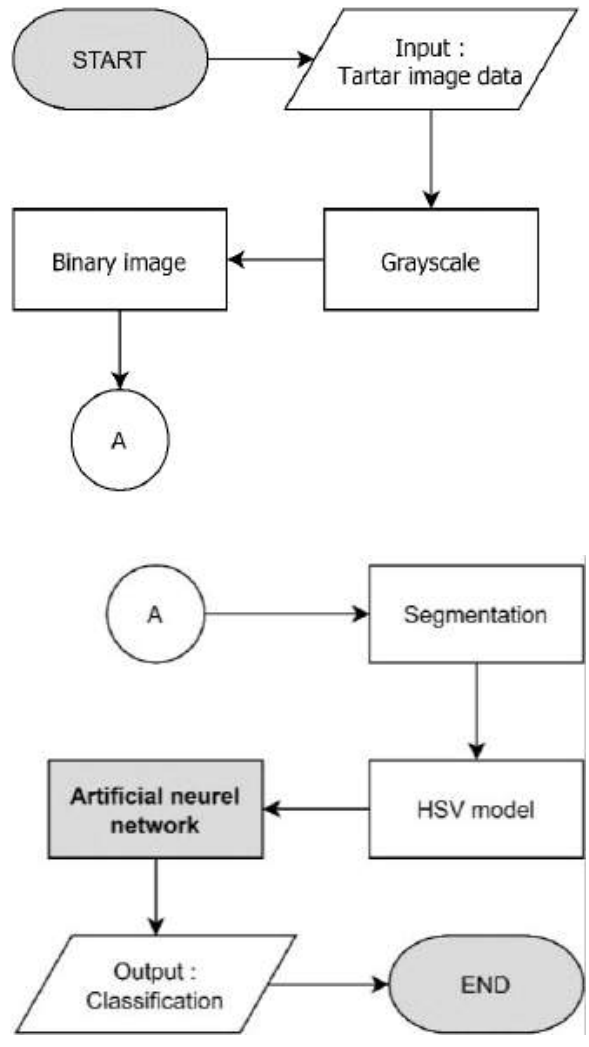

Gambar 1. Flowchart Sistem

\section{a. Input data}

1. Sumber pengumpulan data

- Data primer : Data diperoleh dari hasil pemrosesan sistem

- Data Sekunder : Data gambar diperoleh dari dokter gigi dan siswa akhir dokter gigi dan beberapa dari internet dengan berkonsultasi dengan dokter gigi

2. Metode pengumpulan data

- Wawancara : Melakukan wawancara secara langsung dengan dokter gigi dan mahasiswa akhir dokter gigi.

Data gambar yang diperoleh kemudian dipotong pada are karang gigi dan disamakan dengan resolusi dan ukurannya ( 113X189 piksel dan 3x5 cm ).

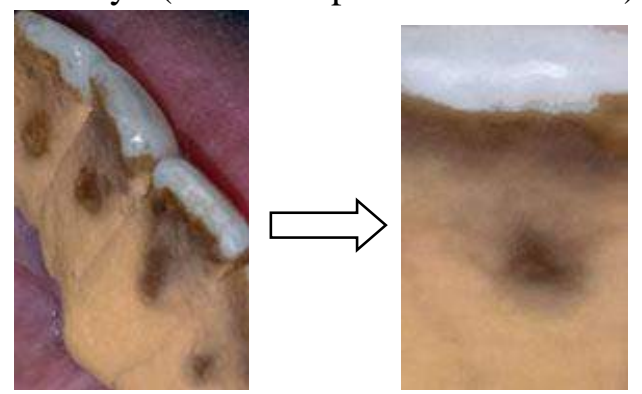

Gambar 2. Proses pemotongan citra

\section{b. Grayscale}

Operasi graysclae adalah operasi pemrosesan citra yang tujuannya adalah untuk mengubah gambar asli menjadi gambar abu-abu, dengan menggunakan nilai abang batas tertentu (thresholding) [6].

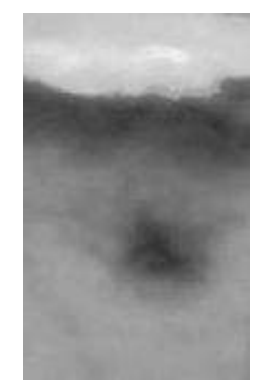

Gambar 3. Hasil proses citra grayscale

\section{c. Binary image}

Citra biner adalah Sebuah citra yang hanya mempunyai 2 nilai yaitu 1 dan 0 . Angka 0 dinyatakan sebagai hitam dan angka 1 dinyatakan sebagai putih. Jika intensitas warna dimulai dari 0 hingga 255 , maka 0 - 128 gelap dan 129 ke atas adalah putih [7]. 


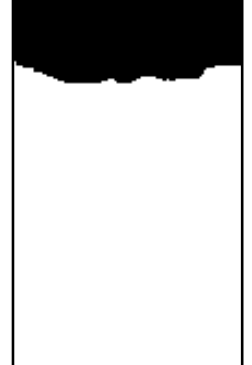

Gambar 4. Hasil proses citra biner

\section{d. Segmentation}

Pada tahap ini. Objek citra akan dipisahkan dengan background-nya. Agar objek citra mudah dianalisa.

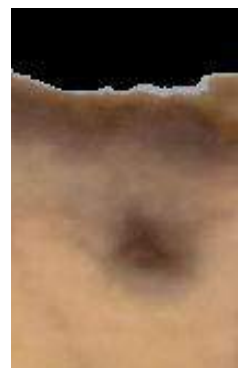

Gambar 5. Hasil Segmentasi

\section{e. HSV model}

Selain model RGB ada juga model HSV (Hue, saturation, value). Nilai ciri Hue adalah nilai panjang suatu gelombang dari warna dominan yang diterima oleh penglihatan, sedangkan nilai ciri saturation adalah akumulasi cahaya putih yang dikombinasikan dengan nilai hue [8].

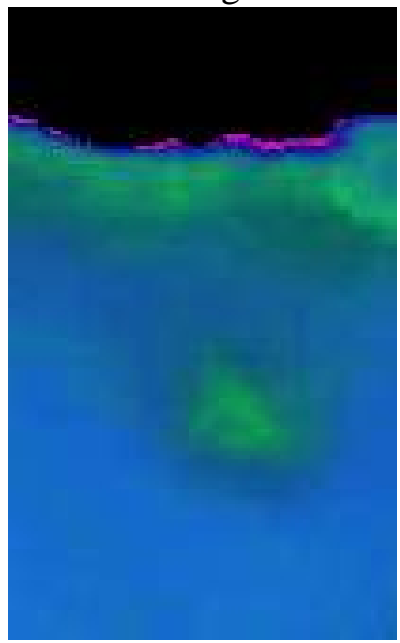

Gambar 7. $H S V$ model

\section{f. Artificial neural network}

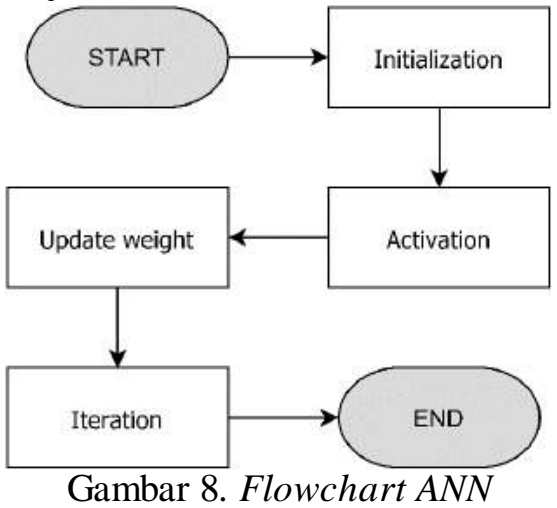

- Initialization

Menginisialisasi masing - masing bobot pada hidden layer dan output layer, kemudian tetapkan fungsi aktivasi yang digunakan pada masing masing layer, setelah itu dilakukan Inisialisasi masing - masing bobot dengan menggunakan bilangan acak dalam jangkauan [$0.5,0.5]$ [9].

- Activation

Mengaktifkan jaringan dengan menerapkan masukan berupa nilai $x_{1}(p), \ldots, x_{n}(p)$ dan keluaran yang diharapkan, seperti $y_{d 1}(p), \ldots, y_{d n}(p)$. Kemudian Hitung keluaran yang diperoleh dari neuron dalam layer tersembunyi dan keluaran akan dihitung daru jumlah neuron dalam layer keluaran.

- Update weight

Bobot setelah diperbarui pada saat eror dirambatkan kembali dalam ANN, eror yang dikembalikan sesuai dengan arah keluarnya sinyal keluaran.

- Iteration

Naikkan satu untuk iterasi p, kembali ke langkah yang ke dua dan ulangi prosesnya hingga kriteria eror tercapai.

3. Hasil dan Pembahasan

a. Implementasi sistem

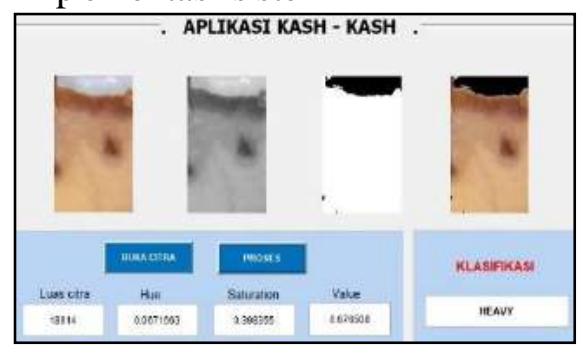

Gambar 9. GUI aplikasi 
Pada GUI aplikasi terdapat 9 keluaran dan 2 tombol. Keluaran yang pertama untuk menampilkan citra asli yang akan di proses. Keluaran yang kedua untuk menampilkan citra abu abu. Keluaran yang ke tiga dan ke empat untuk menampilkan citra biner dan citra hasil segmentasi. Sedangkan keluaran ke lima sampai ke tujuh untuk menampilkan masukkan jaringan saraf tiruan berupa nilai luas citra dan nilai ciri HSV. Dan yang terakhir keluaraan sembilan, untuk menampilkan hasil sistem keseluruhan yaitu hasil klasifikasi. Untuk fungsi 2 tombol pada aplikasi. Tombol pertama sebagai masukan data citra yang akan di uji/latih dan tombol yang kedua untuk memproses keseluruhan sistem .

b. Pengujian sistem

Menurut inisiasi dan tingkat akumulasi bentuk karang gigi. Karang gigi diklasifikasikan menjadi 3 bagian, yaitu sligt ( luas karang gigi $0-1 \mathrm{~mm}$ ), moderate ( luas karang gigi antara 1-2 mm), dan heavy ( luas karang gigi lebih dari $2 \mathrm{~mm}$ ). Pada tahap ini peneliti menggunakan 30 data latih untuk melatih kinerja jaringan saraf tiruan dan menggunkan 2 hidden layer dengan masing masing 100 neuron di setip nilai masukkan sehingga di dapatkan angka validasi dengan format MSE sebesar 0.022203 .

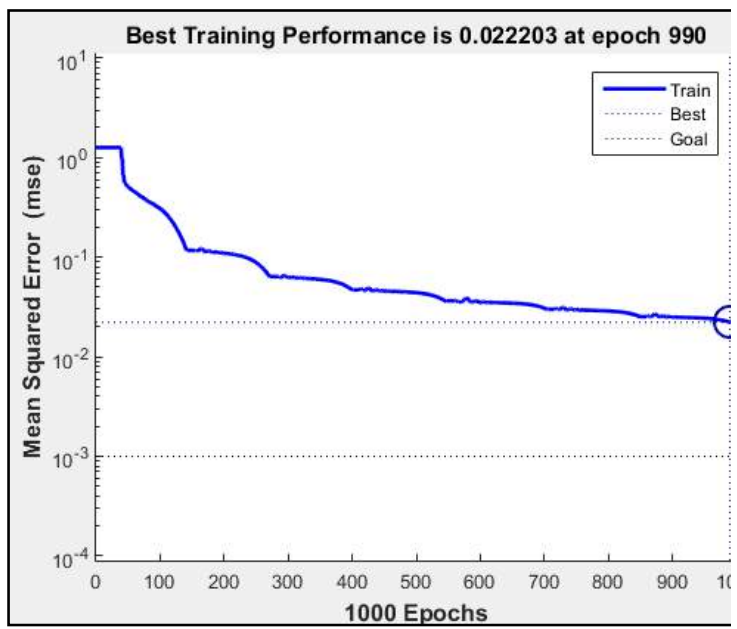

Gambar 10. NIlai MSE

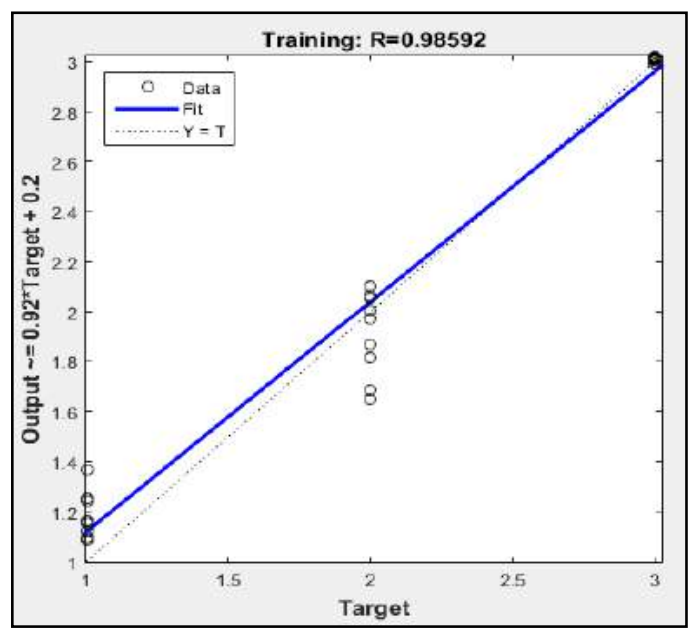

Gambar 11. Koefisien korelasi

Untuk data uji. peneliti menggunakan 20 data uji. Berikut tabel hasil pengujian data uji.

Tabel 1. Hasil data uji sistem

\begin{tabular}{|c|c|c|c|}
\hline No & File name & Target & $\begin{array}{c}\text { Neural } \\
\text { network }\end{array}$ \\
\hline 1 & Heavy-13 & 3 & 3 \\
\hline 2 & Heavy-14 & 3 & $\begin{array}{c}4 / \\
\text { unrecognized }\end{array}$ \\
\hline 3 & Heavy-15 & 3 & 3 \\
\hline 4 & Heavy-16 & 3 & 3 \\
\hline 5 & Heavy-17 & 3 & 3 \\
\hline 6 & Heavy-18 & 3 & 3 \\
\hline 7 & Heavy-19 & 3 & $\begin{array}{c}4 / \\
\text { unrecognized }\end{array}$ \\
\hline 8 & Heavy-20 & 3 & 3 \\
\hline 9 & $\begin{array}{c}\text { Moderate- } \\
10\end{array}$ & 2 & 2 \\
\hline 10 & $\begin{array}{c}\text { Moderate- } \\
11\end{array}$ & 2 & 2 \\
\hline 11 & $\begin{array}{c}\text { Moderate- } \\
12\end{array}$ & 2 & 2 \\
\hline 12 & $\begin{array}{c}\text { Moderate- } \\
13\end{array}$ & 2 & 2 \\
\hline 13 & $\begin{array}{c}\text { Moderate- } \\
14\end{array}$ & 2 & 2 \\
\hline 14 & $\begin{array}{c}\text { Moderate- } \\
15\end{array}$ & 2 & 2 \\
\hline 15 & Slightt-10 & 1 & 1 \\
\hline 16 & Slightt-11 & 1 & 1 \\
\hline 17 & Slightt-12 & 1 & 1 \\
\hline 18 & Slightt-13 & 1 & 1 \\
\hline 19 & Slightt-14 & 1 & 1 \\
\hline 20 & Slightt-15 & 1 & 1 \\
\hline
\end{tabular}

c. Nilai akurasi

Pada tahap ini, nilai akurasi untuk data latih sebesar $100 \%$ sedangkan untuk data uji menghasilkan nilai akurasi sebesar 
$90 \%$. Nilai benar berjumlah 18 data uji dan nilai salah berjumlah 2 data uji (pada Tabel 1.) Berikut rumus perhitungan tingkat akurasi :

$$
\begin{aligned}
& \text { Akurasi }(\%) \\
& =\frac{\text { Jumlah data benar }}{\text { Jumlah keseluhan data }} \times 100
\end{aligned}
$$

$$
\begin{gathered}
\text { Akurasi data uji }=\frac{18}{20} \times 100=90 \% \\
\begin{array}{c}
\text { Akurasi data latih }=\frac{30}{30} \times 100 \\
=100 \%
\end{array}
\end{gathered}
$$

\section{Kesimpulan}

Implementasi aplikasi klasifikasi karang gigi dengan pengolahan citra digital dan metode jaringan saraf tiruan ini menggunakan 50 data citra kalkulus. Untuk data pelatihan, peneliti menggunakan 30 data pelatihan dengan komposisi (12 citra heavy calculus, 9 citra moderate calculus, dan 9 citra slight calculus), memiliki tingkat akurasi sebesar $100 \%$. Untuk data uji, peneliti menggunakan 20 data uji citra karang gigi dengan komposisi (8 citra heavy calculus, 6 citra moderate calculus, dan 6 citra slight calculus). Memiliki akurasi yang cukup baik yaitu $90 \%$. Diharapkan bahwa aplikasi klasifikasi karang gigi ini dapat membantu tenaga medis gigi dalam mengklasifikasi penyakit karang gigi secara digital.

\section{Daftar Pustaka}

[1] B. penelitian dan pengembangan K. K. K. R. Indonesia, "Hasil Utama RISKESDAS 2018," Jakarta, 2018.

[2] T. K. Wajo, "Vol. 17 No.1 Tahun 2018 20," vol. 17, no. 1, pp. 20-24, 2018.

[3] S. Aghanashini, "A Comprehensive Review on Dental Calculus 1," jp-journals10042-1034, vol. 7, pp. 42-50, 2016.

[4] F. Y. Shih, Image Processing and Pattern Recognition: Fundamentals and Techniques. Canada: A JHON WILEY \& SONS INC PUBLICATION, 2010.

[5] Suyanto, ARTIFICIAL INTELLIGENCE ( Searcing, Reasoning, Planning, Learning ), Kedua. Bandung: Informatika Bandung, 2014.

[6] R. Candra, N. Santi, S. Pd, and M. Kom, "Mengubah Citra Berwarna Menjadi Gray - Scale dan Citra biner," vol. 16, no. 1, pp. 14-19, 2011.

[7] N. Nafi, "Algoritma Kohonen dalam Mengubah Citra Graylevel Menjadi Citra Biner," vol. 9, no. 2, pp. 49-55, 2015.

[8] R. D. Kusumanto, A. N. Tompunu, S. Pambudi, J. T. Komputer, and P. N. Sriwijaya, "Klasifikasi Warna Menggunakan Pengolahan Model Warna HSV," vol. 2, no. 2, pp. 83-87, 2011.

[9] A. Fariz, "Peramalan Jumlah Penjualan Mobil dengan Jaringan Syaraf Tiruan Menggunakan Metode Backpropagation.” 